\title{
THE STOCHASTIC UNIT ROOT MODEL AND FRACTIONAL INTEGRATION: AN EXTENSION TO THE SEASONAL CASE
}

\author{
Guglielmo Maria Caporale \\ Brunel University, London
}

Luis A. Gil-Alana

Universidad de Navarra

October 2004

\begin{abstract}
In a recent paper, Yoon (2003) shows that the Stochastic Unit Root (STUR) model is closely related to long memory processes, and, in particular, that it is a special case of an $I(d)$ process, with $d=1.5$. In this paper we further examine this issue by using parametric and semiparametric techniques for modelling long memory. In particular, we extend the analysis by considering both non-normality and seasonality, and shed light, theoretically and by means of Monte Carlo methods, on the relationship between the seasonal STUR and the seasonal I(d) models. The results show that, even in the case of I(1.5) underlying processes, the methods, which are specifically designed for testing I(d) statistical models are not appropriate for testing the STUR model. Moreover, they have in some cases very low power against STUR alternatives.
\end{abstract}

Keywords: Stochastic Unit Roots; Long Memory; Seasonality

JEL classification: $C 22$; C32

Corresponding author: Professor Guglielmo Maria Caporale, Brunel Business School, University, Uxbridge, Middlesex UB8 3PH, UK.

Email: Guglielmo-Maria.Caporale@brunel.ac.uk

Acknowledgements: The second-named author gratefully acknowledges financial support from the Minsterio de Ciencia y Tecnologia (SEC2002-01839, Spain). 


\section{Introduction}

It is widely agreed in the time series literature that many economic and financial time series exhibit strong autocorrelation that can be modelled as a long memory process. Examples are the studies of Diebold and Rudebusch (1989), Baillie (1996), Gil-Alana and Robinson (1997), inter alia. On the other hand, McCabe and Tremayne (1995), Leybourne, McCabe and Treymaine (LMT, 1996), Leybourne, McCabe and Mills (LMM, 1996) and Granger and Swanson (1997) introduced the Stochastic Unit Root (STUR) model, which is a non-linear process that has a unit root only on average. Empirical applications using STUR models include those of Wu and Chen (1997), Bleaney et al. (1999) and Sollis et al. (2000).

The literature on long memory and STUR models has evolved almost independently over the years. Granger (2000) examined the relationship between the two types of models, and, more recently, Yoon (2003) provided both theoretical and Monte Carlo evidence that the STUR model is a particular case of fractional integration with an order of integration equal to 1.5. This is an important result, which implies that taking first differences will not transform a STUR model into a stationary invertible process. Also, it is in stark contrast to the usual assumption that economic and financial series are I(1) (or possibly I(2)) processes. Yoon (2003) applied the tests of LMT (1996) to different $I(d)$ processes, and showed that the highest rejection frequencies were those corresponding to $\mathrm{d}=1.5$. A similar experiment was also conducted by Taylor and van Dijk (2002).

The objective of this paper is three-fold. Firstly, we show by means of Monte Carlo methods that there is no direct link between the STUR model and various widely

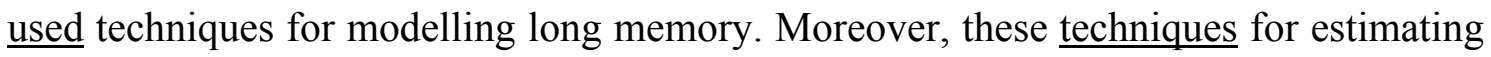
and testing the fractionally differencing parameter can lead to serious bias in the 
inference about the stochastic nature of the process, especially in finite samples. Secondly, we investigate these issues in the context of non-normal disturbances. Finally, we extend the STUR model to the seasonal case, examining its relation to seasonal fractional integration. The outline of the paper is the following. Section 2 briefly describes the STUR and the I(d) statistical models. In Section 3 we present other parametric and semiparametric methods for testing I(d) statistical models, which have been extensively employed in the literature. Section 4 analyses the relationship between the two types of models by means of Monte Carlo experiments. In Section 5 we extend the Monte Carlo analysis to the case of non-Gaussian disturbances. Section 6 examines the case of seasonality, and more Monte Carlo evidence is provided on the relationship between the two types of model. Section 7 contains some concluding comments.

\section{The STUR and I(d) models}

A simple Stochastic Unit Root (STUR) model can be specified as follows:

$$
\begin{gathered}
x_{t}=\left(1+\eta_{t}\right) x_{t-1}+\varepsilon_{t}, \quad t=1,2, \ldots, \\
x_{t}=0, \quad t \leq 0
\end{gathered}
$$

where $\eta_{\mathrm{t}} \approx$ i.i.N $\left(0, \sigma^{2}\right) ; \varepsilon_{\mathrm{t}} \approx$ i.i.N $\left(0, \sigma_{\varepsilon}^{2}\right)$, and $\eta_{\mathrm{t}}$ and $\varepsilon_{\mathrm{t}}$ are assumed to be independent of each other. Clearly, if $\sigma^{2}=0$, (1) becomes a standard unit root model and, given that $\mathrm{E} \eta_{\mathrm{t}}$ $=0, \mathrm{x}_{\mathrm{t}}$ is stationary for some periods and mildly explosive for others. However, on average, $\mathrm{x}_{\mathrm{t}}$ may seem to be $\mathrm{I}(1)$, according to standard tests. The STUR model can be thought of as a special case of the time-varying parameter processes discussed in Andel (1976), with the special feature that the variable is nonstationary. In this sense, STUR models combine unit roots and time-varying parameter characteristics which are relevant for economic time series. Thus, for example, Wu and Chen (1997) found evidence supporting a STUR specification in the case of monthly nominal exchange 
rates, Bleaney et al. (1999) for real exchange rates, and Sollis et al. (2000) for several stock market indices.

Next, we describe the $I(d)$ model. For the moment, we define an $I(0)$ process $\left\{u_{t}\right.$, $\mathrm{t}=0, \pm 1, \ldots\}$ as a covariance stationary process with a spectral density function that is positive and finite at the zero frequency. In this context, we say that a given raw time series $\left\{x_{t}, t=0, \pm 1, \ldots\right\}$ is $I(d)$ if:

$$
(1-L)^{d} x_{t}=u_{t}, \quad t=1,2, \ldots
$$

with $x_{t}=0$ for $t \leq 0^{1}$, where $u_{t}$ is $I(0)$ and where $L$ stands for the lag operator $\left(\operatorname{Lx}_{t}=x_{t-1}\right)$. Note that the polynomial above can be expressed in terms of its Binomial expansion, such that for all real d,

$$
(1-L)^{d}=\sum_{j=0}^{\infty}\left(\begin{array}{l}
d \\
j
\end{array}\right)(-1)^{j} L^{j}=1-d L+\frac{d(d-1)}{2} L^{2}-\ldots
$$

The macroeconomic literature has stressed the cases of $d=0$ and 1 ; however, $d$ can be any real number. Clearly, if $d=0$ in $(1), x_{t}=u_{t}$, and a "weakly autocorrelated" $x_{t}$ is allowed for. However, if $\mathrm{d}>0, \mathrm{x}_{\mathrm{t}}$ is said to be a long memory process, also called "strongly autocorrelated", and so named because of the strong association between observations widely separated in time. As d increases above 0.5 and towards $1, x_{t}$ can be viewed as becoming "more nonstationary", in the sense, for example, that the variance of the partial sums increases in magnitude. These processes were initially introduced by Granger (1980, 1981), Granger and Joyeux (1980) and Hosking (1981) (though earlier work by Adenstedt, 1974, and Taqqu, 1975 shows an awareness of its representation), and were theoretically justified in terms of aggregation of ARMA processes with randomly varying coefficients by Robinson (1978) and Granger (1980). Similarly, Cioczek-Georges and Mandelbrot (1995), Taqqu et al (1997), Chambers (1998) and

\footnotetext{
1 For an alternative definition of fractionally integrated process (the type I class), see Marinucci and Robinson (1999).
} 
Lippi and Zaffaroni (1999) also use aggregation to motivate long memory processes, while Parke (1999) uses a closely related discrete time error duration model. Moreover, Diebold and Inoue (2001) report another source of long memory based on structural change/regime-switching. Empirical applications based on fractional models like (3) can be found, inter alia, in the studies of Diebold and Rudebusch (1989), Baillie and Bollerslev (1994), Gil-Alana and Robinson (1997) and Gil-Alana (2000). ${ }^{2}$

The I(d) model is a particular case of a wider class of models exhibiting long memory. The literature provides several definitions of long memory. The first two definitions are as follows. Given a discrete covariance stationary process, say $\left\{\mathrm{x}_{\mathrm{t}}\right\}$, with autocovariance function $E\left[\left(x_{t}-E x_{t}\right)\left(x_{t-j}-E x_{t}\right)\right]=\gamma_{j}$, according to McLeod and Hipel (1978), the process is a long memory one if:

$$
\lim _{T \rightarrow \infty} \sum_{j=-T}^{j=T}\left|\gamma_{j}\right|
$$

is infinite.

A second way to characterise this process is in the frequency domain. For that purpose, suppose that $\left\{\mathrm{x}_{\mathrm{t}}\right\}$ has spectral density, denoted $\mathrm{f}(\lambda)$, and defined as

$$
f(\lambda)=\frac{1}{2 \pi} \sum_{j=-\infty}^{j=\infty} \gamma_{j} \cos \lambda j, \quad-\pi<\lambda \leq \pi
$$

Then, we say that $\mathrm{x}_{\mathrm{t}}$ displays the property of long memory if the spectral density function has a pole at some frequency $\lambda$ in the interval $[0, \pi]$. A popular technique within this framework is the fractionally integrated model described by (3). It may be shown that this model satisfies: ${ }^{3}$

$$
\gamma_{\mathrm{j}} \approx \mathrm{c}_{1} \mathrm{j}^{2 \mathrm{~d}-1} \quad \text { as } \quad \mathrm{j} \rightarrow \infty, \quad \text { for }\left|\mathrm{c}_{1}\right|<\infty,
$$

and

\footnotetext{
See also Baillie (1996) for an interesting review of I(d) models.

3 Condition (6) is satisfied by the fractional $\operatorname{ARIMA}(0, \mathrm{~d}, 0)$ case. However, when including ARMA components, it is required that all $\gamma_{\mathrm{j}}$ be eventually non-negative.
} 


$$
\mathrm{f}(\lambda) \approx \mathrm{c}_{2} \lambda^{-2 \mathrm{~d}} \quad \text { as } \lambda \rightarrow 0^{+}, \quad \text { for } 0<\mathrm{c}_{2}<\infty
$$

where the symbol $\approx$ means that the ratio of the left-hand-side and the right-hand-side tends to 1 as $\mathrm{j} \rightarrow \infty$ in (6), and as $\lambda \rightarrow 0^{+}$in (7). Conditions (6) and (7) are not always equivalent but Zygmund (1995, Cap.V Sect. 2) and Yong (1974) provide conditions under which both expressions are equivalent.

A final definition of long memory involves the rate of growth of variances of partial sums,

$$
\operatorname{Var}\left(\mathrm{S}_{\mathrm{T}}\right)=\mathrm{O}\left(\mathrm{T}^{2 \mathrm{~d}+1}\right) \text {, with } \quad \mathrm{S}_{\mathrm{T}}=\sum_{\mathrm{t}=1}^{\mathrm{T}} \mathrm{x}_{\mathrm{t}} .
$$

There is a tight connection between this variance-of-partial-sum definition of long memory and the previous ones, since the spectral density at zero frequency is the limit of $(1 / \mathrm{T}) \mathrm{S}_{\mathrm{T}}$. Yoon (2003) related STUR and I(d) models using the third of the above definitions. He showed that if $\sigma^{2}$ in (1) is $\mathrm{O}\left(\mathrm{T}^{-2 \mathrm{k}}\right)$ and $\mathrm{k}>0$, then the variance of the partial sums of $\mathrm{x}_{\mathrm{t}}$ grows at a rate corresponding to an $\mathrm{I}(1.5-\mathrm{k})$ process. In the standard STUR model, $\mathrm{k}=0$, so that a STUR is I(1.5).

\section{Estimation and testing of $\mathbf{I}(\mathbf{d})$ statistical models}

There exist many approaches to estimating and testing the fractional differencing parameter d (see, e.g., Geweke and Porter-Hudak, 1983; Dahlhaus, 1989; Sowell, 1992; Tanaka, 1999; Dolado et al., 2002; etc.). In this paper we will use various parametric and semiparametric methods, already employed in the literature, which have several distinguishing features compared with alternative ones. First, we present a parametric testing procedure due to Robinson (1994a) which is the most efficient method for appropriate (fractional) alternatives. Then, we outline a semiparametric estimation procedure. 


\subsection{A parametric testing procedure}

Robinson (1994a) proposed a Lagrange Multiplier (LM) test of the null hypothesis:

$$
H_{o}: d=d_{o},
$$

in a model given by:

$$
y_{t}=\beta^{\prime} z_{t}+x_{t}, \quad t=1,2, \ldots
$$

and (3), for any real value $d_{0}$, where $y_{t}$ is the time series we observe; $\beta=\left(\beta_{1}, \ldots, \beta_{k}\right)^{\prime}$ is a (kx1) vector of unknown parameters; and $z_{t}$ is a $(k x 1)$ vector of deterministic regressors that may include, for example, an intercept, (e.g., $\mathrm{z}_{\mathrm{t}} \equiv 1$ ), or an intercept and a linear time trend (in case of $\left.z_{t}=(1, t)^{\prime}\right)$. Clearly, $x_{t}$ is the series that is filtered through the fractional differencing polynomial in (3). Specifically, the test statistic is given by:

$$
\hat{R}=\hat{r}^{2} ; \quad \hat{r}=\left(\frac{T}{\hat{A}}\right)^{1 / 2} \frac{\hat{a}}{\hat{\sigma}^{2}}
$$

where $\mathrm{T}$ is the sample size and

$$
\begin{gathered}
\hat{a}=\frac{-2 \pi}{T} \sum_{j=1}^{T-1} \psi\left(\lambda_{j}\right) g\left(\lambda_{j} ; \hat{\tau}\right)^{-1} I\left(\lambda_{j}\right) ; \quad \hat{\sigma}^{2}=\sigma^{2}(\hat{\tau})=\frac{2 \pi}{T} \sum_{j=1}^{T-1} g\left(\lambda_{j} ; \hat{\tau}\right)^{-1} I\left(\lambda_{j}\right) ; \\
\hat{A}=\frac{2}{T}\left(\sum_{j=1}^{T-1} \psi\left(\lambda_{j}\right)^{2}-\sum_{j=1}^{T-1} \psi\left(\lambda_{j}\right) \hat{\varepsilon}\left(\lambda_{j}\right)^{\prime} \times\left(\sum_{j=1}^{T-1} \hat{\varepsilon}\left(\lambda_{j}\right) \hat{\varepsilon}\left(\lambda_{j}\right)^{\prime}\right)^{-1} \times \sum_{j=1}^{T-1} \hat{\varepsilon}\left(\lambda_{j}\right) \psi\left(\lambda_{j}\right)\right) \\
\psi\left(\lambda_{j}\right)=\log \left|2 \sin \frac{\lambda_{j}}{2}\right| ; \quad \hat{\varepsilon}\left(\lambda_{j}\right)=\frac{\partial}{\partial \tau} \log g\left(\lambda_{j} ; \hat{\tau}\right) ; \quad \lambda_{j}=\frac{2 \pi j}{T} ; \quad \hat{\tau}=\arg \min \sigma^{2}(\tau) .
\end{gathered}
$$

$\mathrm{I}\left(\lambda_{\mathrm{j}}\right)$ is the periodogram of $\mathrm{u}_{\mathrm{t}}$ evaluated under the null, i.e.,

$$
\begin{gathered}
\hat{u}_{t}=(1-L)^{d_{o}} y_{t}-\hat{\beta}^{\prime} w_{t} ; \\
\hat{\beta}=\left(\sum_{t=1}^{T} w_{t} w_{t}{ }^{\prime}\right)^{-1} \sum_{t=1}^{T} w_{t}(1-L)^{d_{o}} y_{t} ; \quad w_{t}=(1-L)^{d_{o}} z_{t},
\end{gathered}
$$

and the function $g$ above is a known function coming from the spectral density function of $u_{t}$, 


$$
f\left(\lambda ; \sigma^{2} ; \tau\right)=\frac{\sigma^{2}}{2 \pi} g(\lambda ; \tau), \quad-\pi<\lambda \leq \pi
$$

Note that this test is purely parametric and, therefore, it requires specific modelling assumptions about the short memory specification of $\mathrm{u}_{\mathrm{t}}$. Thus, if $\mathrm{u}_{\mathrm{t}}$ is white noise, $\mathrm{g} \equiv 1$, and if it is an AR process of the form $\phi(\mathrm{L}) \mathrm{u}_{\mathrm{t}}=\varepsilon_{\mathrm{t}}, \mathrm{g}=\left|\phi\left(\mathrm{e}^{\mathrm{i} \lambda}\right)\right|^{-2}$, with $\sigma^{2}=\mathrm{V}\left(\varepsilon_{\mathrm{t}}\right)$, so that the AR coefficients are a function of $\tau{ }^{4}$

Based on the null hypothesis $H_{o}(9)$, Robinson (1994a) established that under certain regularity conditions: ${ }^{5}$

$$
\hat{R} \rightarrow_{d} \quad \chi_{1}^{2}, \quad \text { as } \quad T \rightarrow \infty
$$

Thus, unlike in other procedures, we are in a classical large-sample testing situation for the reasons explained in Robinson (1994a), who also showed that the tests are efficient in the Pitman sense against local departures from the null. Because $\hat{R}$ involves a ratio of quadratic forms, its exact null distribution can be calculated under Gaussianity via Imhof's algorithm. However, a simple test is approximately valid under much wider distributional assumptions: an approximate one-sided $100 \alpha \%$ level test of $\mathrm{H}_{\mathrm{o}}(9)$ against the alternative: $H_{a}: d>d_{o}\left(d<d_{o}\right)$ will be given by the rule: "Reject $H_{o}$ if $\hat{r}>z_{\alpha}(\hat{r}<-$ $\mathrm{z}_{\alpha}$ )", where the probability that a standard normal variate exceeds $z_{\alpha}$ is $\alpha$. This version of the tests of Robinson (1994a) was used in empirical applications in Gil-Alana and Robinson (1997) and Gil-Alana (2000), and other versions of his tests, based on seasonal (quarterly and monthly) and cyclical data respectively, can be found in GilAlana and Robinson (2001) and Gil-Alana (1999, 2001).

There exist other procedures for estimating and testing parametrically the fractionally differenced parameter, some of them also based on the likelihood function. As in other standard large-sample testing situations, Wald and LR test statistics against

\footnotetext{
${ }^{4}$ If $\mathrm{u}_{\mathrm{t}}$ is $\operatorname{AR}(1): \mathrm{u}_{\mathrm{t}}=\alpha \mathrm{u}_{\mathrm{t}-1}+\varepsilon_{\mathrm{t}}, \mathrm{g}(\lambda ; \tau)=\left|1-\alpha \mathrm{e}^{\mathrm{i} \lambda}\right|^{-2}$, so that $\alpha=\tau$.
} 
fractional alternatives will have the same null and local limit theory as the LM tests of Robinson (1994a). Sowell (1992) essentially employed such a Wald testing procedure, but his method requires an efficient estimate of $d$, and, while such estimates can be obtained, no closed-form formulae are available, and therefore the LM procedure of Robinson (1994a) seems computationally more attractive.

A problem with parametric procedures is that the model must be correctly specified; otherwise, the estimates can be inconsistent. In fact, misspecification of the short run components of the process may invalidate the estimation of the long run parameter $\mathrm{d}$. This is the main reason for also using here the semiparametric procedure which we now describe.

\subsection{A semiparametric estimation procedure}

There exist several methods for estimating the fractional differencing parameter in a semiparametric way. Examples are the log-periodogram regression estimator (LPE), initially proposed by Geweke and Porter-Hudak (1983) and modified later by Künsch (1986) and Robinson (1995a), the average periodogram estimator (APE, Robinson, 1994b) and the quasi maximum likelihood estimator (QMLE, Robinson, 1995b). In this paper we use the QMLE of Robinson (1995b) which we now describe.

The QMLE is essentially a local "Whittle estimator" in the frequency domain, based on a band of frequencies that degenerates to zero. The estimator is implicitly defined by:

$$
d_{1}=\arg \min { }_{d}\left(\log \overline{C(d)}-2 d \frac{1}{m} \sum_{j=1}^{m} \log \lambda_{j}\right),
$$

\footnotetext{
5 These conditions are very mild, regarding technical assumptions to be satisfied by $\psi(\lambda)$.
} 


$$
\overline{C(d)}=\frac{1}{m} \sum_{j=1}^{m} I\left(\lambda_{j}\right) \lambda_{j}^{2 d}, \quad \lambda_{j}=\frac{2 \pi j}{T}, \frac{m}{T} \rightarrow 0 .
$$

where $I\left(\lambda_{j}\right)$ is the periodogram of the raw series, and $d \in(-0.5,0.5) .{ }^{6}$ Under finiteness of the fourth moment and other mild conditions, Robinson (1995a) proved that:

$$
\sqrt{\mathrm{m}}\left(\hat{\mathrm{d}}-\mathrm{d}_{\mathrm{o}}\right) \rightarrow_{\mathrm{d}} \mathrm{N}(0,1 / 4) \quad \text { as } \mathrm{T} \rightarrow \infty
$$

where $d_{o}$ is the true value of $d$, with the only additional requirement that $m \rightarrow \infty$ slower than T. Robinson (1995a) showed that m must be smaller than $T / 2$ to avoid aliasing effects. A multivariate extension of this estimation procedure can be found in Lobato (1999).

Other methods also based on semiparametric models (like the APE and the LPE) have been applied to economic time series (see, e.g. Gil-Alana, 2002). However, in the present study we use the QMLE, primarily because of its computational simplicity. Note that this also means that we do not need to employ any additional user-chosen numbers in the estimation (which is instead required by the LPE and the APE). Also, we do not have to assume Gaussianity in order to obtain an asymptotic normal distribution, the QMLE being more efficient than the LPE.

\section{Simulation results}

Yoon (2003) showed that the STUR and the I(d) models are related, specifically that in the standard STUR model, $d=1.5$. Several Monte Carlo experiments have confirmed this result. Taylor and van Dijk (2002) carried out an extensive simulation study of the performance of the STUR tests of LMT (1996) applied to I(d) processes. They noticed that the rejection frequencies of the tests initially increased with $\mathrm{d}$, and then decreased 
as $d \rightarrow 2$. New simulations were conducted by Yoon (2003), who obtained the highest frequencies at $d=1.5$. In these two papers, $I(d)$ processes are generated, and then the tests of LMM (1996) are performed. Here, the experimental setup is the opposite. We generate a STUR model, obtained from Gaussian series, using the routines GASDEV and RAN3 of Press, Flannery, Teukolsky and Vetterling (1986), and then perform the tests for long memory described in Section 3.

In Tables $1-4$ we report the rejection frequencies of the version of the tests of Robinson (1994a) described in Section 3.1, testing $H_{o}(9)$ in (3) for values $d_{o}=0,(0.25)$, 2, for sample sizes $\mathrm{T}=100,(100), 500,1000$ and 2000. In Tables 1 and 3 the tests are performed assuming that $u_{t}$ in (3) is white noise, while Tables 2 and 4 report the results assuming that $\mathrm{u}_{\mathrm{t}}$ is an $\mathrm{AR}(1)$ process. First, in Tables 1 and 2, we assume that the true model is a simple STUR model as in (1). In Tables 3 and 4, the true model is given by (1) with

$$
\eta_{t}=\alpha \eta_{t-1}+v_{t}, \quad t=1,2, \ldots
$$

where $\alpha=0.50$ and $\mathrm{v}_{\mathrm{t}}$ is i.i.d. $\left(0, \sigma^{2}\right)$ independent of $\varepsilon_{\mathrm{t}}$. Then, $\mathrm{y}_{\mathrm{t}}$ is a first order random coefficient autoregressive (RCAR(1)) model with mean unit root, called STUR by LMT (1996) and Granger and Swanson (1997).

\section{(Insert Tables 1 and 2 about here)}

In Table 1, where $u_{t}$ is assumed to be white noise, we notice, first of all, that the lowest rejection probabilities are obtained at $d=0.75$ with $T=100$, and at $d=0.50$ for all the other sample sizes. Increasing $\mathrm{T}$, the rejection frequencies also increase, and, if $\mathrm{T}$ $\geq 500$, the values are exactly 1 for all $d$ except 0.50 . If we assume that $u_{t}$ is $A R(1)$, the rejection frequencies are relatively high in all cases, being higher than 0.9 for $d \geq 0.25$ even for $\mathrm{T}=100$. Here, the lowest probabilities are obtained at $\mathrm{d}=0$. This might be due

6 Velasco $(1999 \mathrm{a}, \mathrm{b})$ has recently shown that the fractionally differencing parameter can also be 
to the fact that the AR estimates are of the Yule-Walker type, which entails roots that, though automatically less than 1 in absolute value, can be arbitrarily close to unity, and thus might be competing with $\mathrm{d}$ in describing nonstationarity.

\section{(Insert Tables 3 and 4 about here)}

Tables 3 and 4 are analogous to Tables 1 and 2 but are based on the alternative model given by (1) and (14). The rejection frequencies for the case of white noise disturbances are given in Table 3. We can see that the values are much lower than in Table 1, and the lowest probabilities are obtained at $\mathrm{d}=0.75$ for all $\mathrm{T}$, and, although the values increase with $T$, they only reach 1 for $d=1.75$ and 2 even with $T=2000$. If $u_{t}$ is $\operatorname{AR}(1)$, the lowest probabilities are obtained with $d=0$, which is consistent with the results in Table 2, and, although the values in this table are smaller, they are in all cases close to 1 for $\mathrm{T}=2000$.

The results reported in Tables $1-4$ clearly contradict the findings of Yoon (2003), who argues that the STUR model corresponds to an I((1.5) model. Two points are noteworthy. The first is that Robinson's (1994a) procedure is fully parametric and, therefore, specifies the model in its complete form, i.e.,

$$
(1-\mathrm{L})^{\mathrm{d}_{\mathrm{o}}} \mathrm{X}_{\mathrm{t}}=\varepsilon_{\mathrm{t}},
$$

in Tables 1 and 3, and

$$
(1-L)^{d_{o}} x_{t}=u_{t}, \quad u_{t}=\alpha u_{t-1}+\varepsilon_{t},
$$

in Tables 2 and 4, both of which are clearly different from the theoretical STUR model (1) (and (14)). The second is related to the definition of I(d) used by Yong (2003). This is based on the concept of the rate of growth of the variances of the partial sums, while the I(d) model used in Robinson's (1994a) tests is simply defined as a process that is $I(0)$ once it has been $d_{0}$-differenced. Thus, though both processes share the same rate of

consistently and semiparametrically estimated in nonstationary contexts by means of tapering. 
decay of the autocorrelations, they are not identical, explaining why the tests reject the null with $\mathrm{d}=1.5$.

\section{(Insert Tables 5 and 6 about here)}

In order to solve the first of these two problems, we report, in Tables 5 and 6 , the rejection probabilities using the semiparametric method presented in Section 3.2. Using the same $d_{0}$-values and sample sizes as in Tables $1-4$, we calculate the rejection frequencies for values of the bandwidth parameter $\mathrm{m}=\mathrm{T} / 10, \mathrm{~T} / 5, \mathrm{~T} / 4, \mathrm{~T} / 3$ and $(\mathrm{T} / 2)-1 .^{7}$ Table 5 uses as the true model the simple STUR model (1), while its more elaborated form (1) and (14)) is used in Table 6. We notice that the null of $d=1.5$ is always rejected with a probability higher than 0.9 , which is consistent with the results produced by the parametric procedure. Using the simple model (1), the lowest rejection probabilities are obtained at $d=1$ (Table 5), implying that the STUR specification is easily confused with the I(1) process. Using the model with AR(1) components ((1) and (14)) the lowest values are obtained now at $d=0.5$ (Table 6).

To sum up, both parametric and semiparametric methods tend to reject the hypothesis of I(1.5) processes for the STUR model. Moreover, they have in some cases very low power against the STUR alternatives and tend not to reject the null of $d=0.5$ or $\mathrm{d}=1$. This is a serious problem for the practitioner, since if the true process follows a STUR model, the two methods described in Section 3 can produce spurious results about the order of integration of the series, with the implications that this might have in terms of theorising, modelling and/or forecasting.

\section{The STUR model with non-Gaussian disturbances}

\footnotetext{
7 Some attempts to calculate the optimal bandwidth numbers have been examined in Delgado and Robinson (1996) and Robinson and Henry (1996). However, in the case of the Whittle estimator (QMLE), the use of optimal values has not been theoretically justified.
} 
In this section, the Monte Carlo experiments conducted in Section 4 are extended to the case where the true model is a STUR one, but non-Gaussian disturbances are used. In particular, we assume a $t_{3}$ distribution in $\varepsilon_{t}$, in $\eta_{t}$, and in both of them. The results were very similar in all cases. Thus, we only report those corresponding to the $t_{3}$ distribution for $\varepsilon_{t}$.

\section{(Insert Tables 7 - 10 about here)}

Tables $7-10$ are analogous to Tables $1-4$, but based on non-Gaussian disturbances. The results are completely in line with those obtained in the case of Gaussian $u_{t}$. In Table 7 we consider the simple STUR model (1), and perform Robinson's (1994a) tests with a white noise $u_{t}$. (Note that Gaussianity is not required in the tests of Robinson, 1994a - the only requirement is a moment condition of order 2). We see that, similarly to Table 1 , if $T=100$, the lowest values occur at $d=0.50$. When imposing $\operatorname{AR}(1) u_{t}$ in the specification of the tests (Table 8), the lowest values occur at $d$ $=0$, and the same pattern as in Tables 7 and 8 is obtained when using the more elaborated versions of the STUR (STUR ${ }^{*}$ ) model in Tables 9 and 10.

\section{A seasonal STUR model and seasonal fractional integration}

The STUR specification described in Section 2 can be easily extended to the seasonal case by considering the model,

$$
x_{t}=\left(1+\eta_{t}\right) x_{t-s}+\varepsilon_{t}, \quad t=1,2, \ldots
$$

where $\mathrm{s}$ again corresponds to the number of time periods within a year $(\mathrm{s}=4$ with quarterly data; $\mathrm{s}=12$, monthly; etc. $)$, with $\eta_{\mathrm{t}} \approx \mathrm{N}\left(0, \sigma^{2}\right)$ and $\varepsilon_{\mathrm{t}} \approx$ i.i.N $\mathrm{N}\left(0, \sigma_{\varepsilon}^{2}\right)$. If $\sigma^{2}=0, \mathrm{x}_{\mathrm{t}}$ becomes a seasonal unit root model of the form advocated by Dickey, Hasza and Fuller (DHF, 1984), Hylleberg, Engle, Granger and Yoo (HEGY, 1990), Tam and Reinsel 
(1997) and others. As in the non-seasonal case, given that $E \eta_{t}=0$, on average $x_{t}$ may appear to be a seasonal I(1) process.

On the other hand, in fractional contexts, the I(d) model presented in Section 2 can be extended to

$$
\left(1-L^{s}\right)^{d} x_{t}=u_{t}, \quad t=1,2, \ldots
$$

where $u_{t}$ is $I(0)$, and $d$ can be any real number. Here, the seasonal fractional polynomial can also be expressed in terms of its Binomial expansion, such that, for all real $d$,

$$
\left(1-L^{\mathrm{s}}\right)^{\mathrm{d}}=\sum_{\mathrm{j}=0}^{\infty}\left(\begin{array}{l}
\mathrm{d} \\
\mathrm{j}
\end{array}\right)(-1)^{\mathrm{j}} \mathrm{L}^{\mathrm{sj}}=1-\mathrm{d} \mathrm{L}^{\mathrm{s}}+\frac{\mathrm{d}(\mathrm{d}-1)}{2} \mathrm{~L}^{2 \mathrm{~s}}-\ldots .
$$

We can test the same null hypothesis (9) in the model given by (10) and (16) and the test statistic takes a similar form as $\hat{R}$ in (11), the only difference being in the estimated residuals, which are now:

$$
\hat{u}_{t}=\left(1-L^{S}\right)^{d_{o}} y_{t}-\hat{\beta}^{\prime} w_{t} ; \hat{\beta}=\left(\sum_{t=1}^{T} w_{t} w_{t}\right)^{-1} \sum_{t=1}^{T} w_{t}\left(1-L^{S}\right)^{d_{o}} y_{t} ; \quad w_{t}=\left(1-L^{S}\right)^{d_{o}} z_{t},
$$

and the functional form of $\psi\left(\lambda_{j}\right)$, which is, for the case of $s=4$ :

$$
\psi\left(\lambda_{\mathrm{j}}\right)=\log \left|\sin \frac{\lambda_{\mathrm{j}}}{2}\right|+\log \left(2 \cos \frac{\lambda_{\mathrm{j}}}{2}\right)+\log \left|2 \cos \lambda_{\mathrm{j}}\right|
$$

Robinson (1994a) showed that the test is still characterised by the same standard null limit distribution. Empirical applications of this version of Robinson's (1994a) tests can be found in Gil-Alana and Robinson (2001) and Gil-Alana (2002), inter alia.

It can be easily proved that, after recursive substitutions, (15) becomes:

$$
\left.\mathrm{x}_{\mathrm{t}}=\sum_{\mathrm{j}=0}^{\operatorname{int}\left[\frac{\mathrm{t}-1}{\mathrm{~s}}\right]}\right]\left[\prod_{\mathrm{k}=0}^{\operatorname{int}\left[\frac{\mathrm{j}-1}{\mathrm{~s}}\right]}\left(1+\eta_{\mathrm{t}-\mathrm{ks}}\right)\right] \varepsilon_{\mathrm{t}-\mathrm{sj}}
$$

implying that 


$$
\left(1-L^{\mathrm{s}}\right) \mathrm{x}_{\mathrm{t}}=\left(\eta_{\mathrm{t}} \sum_{\mathrm{j}=0}^{\operatorname{int}\left[\frac{\mathrm{t}-2}{\mathrm{~s}}\right]}\left[\begin{array}{c}
\operatorname{int}\left[\frac{\mathrm{j}-1}{\mathrm{~s}}\right] \\
\prod_{\mathrm{k}=0}\left(1+\eta_{\mathrm{t}-\mathrm{ks}-1}\right.
\end{array}\right]\right)+\varepsilon_{\mathrm{t}} .
$$

Following Abadir (2003), it can be proved that $\left(1-\mathrm{L}^{\mathrm{s}}\right) \mathrm{x}_{\mathrm{t}}$ can be approximated by taking the linear terms in the product of the $\eta_{s}$, such that $\left(1-L^{s}\right) x_{t}$ can be expressed as $\eta_{t} S_{t-1}+$ $\varepsilon_{t}$, where $S_{t}=\sum_{i=1}^{t} x_{i}$, and some of the $\eta_{s}$ will be exactly 0 for the non-seasonal values.

Using now the same proposition as in Yoon (2003), if $\sigma^{2}=\mathrm{O}\left(\mathrm{T}^{-2 \mathrm{k}}\right)$ and $\mathrm{k}>0$, the variance of the partial sums of $x, \operatorname{Var}\left(\sum_{i=1}^{T} x_{i}\right)$, grows at a rate corresponding to $I(1.5-k)$ behaviour. Thus, in the standard case, $\mathrm{k}=0$, so that the seasonal STUR model is I(1.5).

In Tables 11 - 14 we perform the same type of analysis as before, but focus on the seasonal case with $s=4$. Thus, we compute the rejection frequencies of the new tests, for the same $\left(\mathrm{d}_{\mathrm{o}} / \mathrm{T}\right)$ combinations as in the previous cases, using the versions of Robinson's (1994a) tests for seasonality. In Tables 11 and 13 we assume that $u_{t}$ is a white noise process, while Tables 12 and 14 report the results based on a seasonal $\mathrm{AR}(1)$ process of the form:

$$
u_{t}=\alpha u_{t-4}+\varepsilon_{t},
$$

with $\alpha=0.50$ and white noise $\varepsilon_{t}$. Tables 12 and 14 consider a more elaborated version of the STUR model, consisting of (1) and

$$
\eta_{t}=\alpha \eta_{t-4}+v_{t}
$$

with white noise $\mathrm{v}_{\mathrm{t}}$, independent of $\varepsilon_{\mathrm{t}}$.

\section{(Insert Tables 11 -14 about here)}

As expected, the same problem encountered before occurs again, and the null hypothesis of $d=1.5$ is almost always rejected. Starting with the simple STUR model, the lowest rejection frequencies occur at $d=0.5$ when white noise disturbances are 
assumed, and at $d=0.25$ with $\operatorname{AR}(1) u_{t}$ (in Tables 11 and 12 respectively), and the same happens when the model with (16) and (17) is employed (Tables 13 and 14).

Thus, as in the non-seasonal case, we do not find evidence of $\mathrm{I}(1.5)$ in the seasonal STUR model when using the seasonal version of Robinson's (1994a) tests, and, more worryingly, if the sample size is not very large, the tests tend not to reject the null for $\mathrm{d}=0.25$ or $\mathrm{d}=0.5$ in many cases.

\section{Conclusions}

This paper makes a contribution to the recent literature by examining if long memory and stochastic unit root models, which have evolved independently, are in fact closely related as claimed by other authors as well (see, e.g., Granger, 2000). Specifically, in a recent study, Yoon (2003) shows that the Stochastic Unit Root (STUR) model is a special case of an $\mathrm{I}(\mathrm{d})$ process, with $\mathrm{d}=1.5 .^{8}$ The present paper further examines this issue by means of parametric and semiparametric techniques for modelling long memory. Moreover, it extends the analysis by considering both non-normality and seasonality, and shows theoretically and by means of Monte Carlo simulations that the seasonal stochastic unit root model and seasonal long memory are closely related.

Our findings suggest that the current practice of assuming that most economic variables are $\mathrm{I}(1)$ or at most $\mathrm{I}(2)$ is not warranted, which obviously has important implications for economic modelling and policy-making. However, they also call into question the adequacy of STUR specifications for many economic and financial series. More precisely, both seasonal and non-seasonal STUR models imply I(1.5) processes, in the sense that the autocorrelation function of their first differences decays at a hyperbolic rate according to the law $\mathrm{O}\left(\mathrm{T}^{2 \mathrm{~d}+1}\right)$. Our analysis, which is based on various

8 Other, more elaborate, STUR models have been proposed by Granger and Swanson (1997), Brandt (1996), Pourahmandi (1989), etc. 
parametric and semiparametric techniques for estimating the fractional differencing parameter widely used in the literature, shows that, indeed, the same hyperbolic decay property characterises both types of models. However, it also implies a strong rejection of the null hypothesis represented by this particular law of motion. In fact, if one has reasons to assume that the process underlying the series is of a STUR type, we would highly recommend using at the outset procedures which are specifically designed for testing STUR specifications, such as those developed by McCabe and Tremayne (1995), Leybourne et al. (LMM, 1996), Leybourne et al. (LMT, 1996), Distaso (2003) etc. On the other hand, if the correlograms show some evidence of a hyperbolic decay in the autocorrelations and there is no prior evidence of a STUR process, standard approaches based on I(d) statistical models should be used. 


\section{References}

Abadir, K., 2003, Cointegration theory, equilibrium and disequilibrium economics, forthcoming in Manchester School.

Adenstedt, R.K., 1974, On large sample estimation for the mean of a stationary random sequence, Annals of Statistics 2:,259-272.

Andel, J., 1976, Autoregressive series with random parameters, Math Operationsforsch u. Statistics 7, 735-741.

Baillie, R.T., 1996, Long memory processes and fractional integration in econometrics, Journal of Econometrics 73, 5-59.

Baillie, R.T. and T. Bollerslev, 1994, Cointegation, Fractional Cointegration and Exchange Rate Dynamics, Journal of Finance 49, 737-45.

Bleaney, M.F., S.J. Leybourne, and P. Mizen, 1999, Mean reversion of real exchange rates in high inflation countries, Southern Economic Journal 65, 839-854.

Brandt, A., 1986, The stochastic equation $Y_{n+1}=A_{n} Y_{n}+B_{n}$ with stationary coefficients, Advances in Applied Probability 18, 211-220.

Chambers, M., 1998, Long memory and aggregation in macroeconomic time series, International Economic Review 39, 1053-1072.

Cioczek-Georges, R. and B.B. Mandelbrot, 1995, A class of micropulses and antipersistent fractional Brownian motion, Stochastic Processes and Their Applications 60, $1-18$.

Dahlhaus, R., 1989, Efficient parameter estimation for self-similar process, Annals of Statistics 17, 1749-1766.

Delgado, M.A. and P.M. Robinson, 1996, Optimal spectral bandwidth for long memory, Statistica Seneca 6, 97-112.

Dickey, D.A., D.P. Hasza and W.A. Fuller, 1984, Testing for unit roots in seasonal time series, Journal of the American Statistical Association 79, 355-367.

Diebold, F.X. and A. Inoue, 2001, Long memory and regime switching, Journal of Econometrics 105, 131-159.

Diebold, F.X. and G. Rudebusch, 1989, Long memory and persistence in aggregate output, Journal of Monetary Economics 24, 189-209.

Distaso, W., 2003, Testing for a random walk in a random coefficient autoregressive model, Manuscript.

Dolado, J.J., J. Gonzalo and L. Mayoral, 2002, A fractional Dickey-Fuller tests, Econometrita 70, 1973-2006. 
Geweke, J. and S. Porter-Hudak, 1983, The estimation and application of long memory time series models, Journal of Time Series Analysis 4, 221-238.

Gil-Alana, L.A., 1999, Testing of fractional integration with monthly data, Economic Modelling 16, 613-629.

Gil-Alana, L.A., 2000, Mean reversion in the real exchange rates, Economics Letters 16 285-288.

Gil-Alana, L.A., 2001, Testing of stochastic cycles in macroeconomic time series, Journal of Time Series Analysis 22, 411-430.

Gil-Alana, L.A., 2002, Seasonal long memory in the aggregate output, Economics Letters 74, 333-337.

Gil-Alana, L.A. and P.M. Robinson, 1997, Testing of unit roots and other nonstationary hypotheses in macroeconomic time series, Journal of Econometrics 80, 241-268.

Gil-Alana, L.A. and P.M. Robinson, 2001, "Testing seasonal fractional integration in the UK and Japanese consumption and income", Journal of Applied Econometrics, 16, 95-114.

Granger, C.W.J., 1980, Long memory relationships and the aggregation of dynamic models, Journal of Econometrics 14, 227-238.

Granger, C.W.J., 1981, Some properties of time series data and their use in econometric model specification, Journal of Econometrics 16, 121-130.

Granger, C.W.J., 2000, Current perspectives on long memory processes, Academia Economic Papers 28, 1-16.

Granger, C.W.J. and R. Joyeux, 1980, An introduction to long memory time series and fractionally differencing, Journal of Time Series Analysis 1, 15-29.

Granger, C.W.J. and N.R. Swanson, 1997, An introduction to stochastic unit root processes, Journal of Econometrics 80, 35-62.

Hosking, J.R.M., 1981, Fractional differencing, Biometrika 68, 168-176.

Hylleberg, S., R.F. Engle, C.W.J. Granger and B.S. Yoo, 1990, Seasonal integration and cointegration, Journal of Econometrics 44, 215-238.

Kunsch, H., 1986, Discrimination between monotonic trends and long-range dependence, Journal of Applied Probability 23, 1025-1030.

Leybourne, S.J., B.P.M. McCabe and A.R. Tremayne, 1996, Can economic time series be differenced to stationarity? Journal of Business and Economic Statistics 14, 435-446. 
Leybourne, S.J., B. P.M. McCabe and T.C. Mills, 1996, Randomized unit root processes for modelling and forecasting financial time series: Theory and application, Journal of Forecasting 15, 273-280.

Lippi, M. and P. Zaffaroni, 1999, Contemporaneous aggregation of linear dynamic models in large economies, Manuscript, Research Department, Bank of Italy.

Lobato, I., 1999, A semiparametric two-step estimator for a multivariate long memory process, Journal of Econometrics 73, 303-324.

Marinucci, D. and P.M Robinson, 1999, Semiparametric fractional cointegration models, Journal of Statistical Planning and Inference 80, 111-122.

McCabe, B.M.P. and A.R. Tremayne, 1995, Testing a time series for difference stationarity, Annals of Statistics 23, 1015-1028.

McLeod, A.I. and K.W. Hipel, 1978, Preservatgion of the rescaled adjusted range. A reassessment of the Hurst phenomenon, Water Resources Research 14, 491-507.

Parke, W.R., 1999, What is fractional integration?, The Review of Economics and Statistics 81, 632-638.

Pourahmadi, M., 1988, Stationarity of the solution of Xt $=$ AtXt-1 $+\varepsilon t$ and analysis of non-Gaussian dependent random variables, Journal of Time Series Analysis 9, 225-239.

Press, W.H.,, Flannery, B.P., Teukolsky, S.A. and Wetterling, W.T., 1986, Numerical recipes: The art of scientific computing: Cambridge University Press, Cambridge.

Robinson, P.M., 1978, Statistical inference for a random coefficient autoregressive model, Scandinavian Journal of Statistics 5, 163-168.

Robinson, P.M., 1994a, Efficient tests of nonstationary hypotheses, Journal of the American Statistical Association 89, 1420-1437.

Robinson, P.M., 1994b, Semiparametric analysis of long memory time series, Annals of Statistics 22, 515-539.

Robinson, P.M., 1995a, Gaussian semiparametric estimation of long range dependence, Annals of Statistics 23, 1630-1661.

Robinson, P.M., 1995b, Log-periodogram regression of time series with long range dependence, Annals of Statistics 23, 1048-1072.

Robinson, P.M. and M. Henry, 1996, Bandwidth choice in Gaussian semiparametric estimation of long-range dependence, in P.M. Robinson and M. Rosenblatt eds. Athens Conference on Applied Probability in Time Series Analysis, Vol.II, New York, 220232.

Sollis, R., S.J. Leybourne and P. Newbold, 2000, Stochastic unit root modelling of stock price indices, Applied Financial Economics 10, 311-315. 
Sowell, F., 1992, Modelling long run behaviour with the fractional ARIMA model, Journal of Monetary Economics 29, 277-302.

Tam, W. and G.C. Reinsel, 1997, Tests for seasonal moving average unit root in ARIMA models, Journal of the American Statistical Association 92, 725-738.

Tanaka, K., 1999, The nonstationary fractional unit root, Econometric Theory 15, 549582.

Taqqu, M.S., 1975, Weak convergence to fractional motion and to the Rosenblatt process, Z. Wahrscheinlichkeitstheorie verw. Geb. 31, 287-302.

Taqqu, M.S., W. Willinger and R. Sherman, 1997, Proof of a fundamental result in selfsimilar traffic modelling, Computer Communication Review 27, 5-23.

Taylor, A.M.R and D. van Dijk, 2002, Can tests for stochastic unit roots provide useful portmanteau tests for persistence? Oxford Bulletin of Economics and Statistics 64, 381397.

Velasco, C., 1999a, Nonstationary log-periodogram regression, Journal of Econometrics 91, 299-323.

Velasco, C., 1999b,. Gaussian semiparametric estimation of nonstationary time series, Journal of Time Series Analysis 20, 87-127.

Velasco, C., 2000, Non-Gaussian log-periodogram regression, Econometric Theory 16, 44-79.

$\mathrm{Wu}$, J.-L. and S.-L Chen, 1997, Can nominal exchange rates be differenced to stationarity? Economic Letters 55, 397-402.

Yong, C.H., 1974, Asymptotic behaviour of trigonometric series, Hong-Kong, Chinese University of Hong-Kong.

Yoon, G., 2003, Stochastic unit roots, long memory and I(1.5), Department of Economics and Related Studies, University of York, Working Paper.

Zygmund, A., 1995, Trigonometric series, Cambridge University Press, Cambridge. 


\begin{tabular}{|c|c|c|c|c|c|c|c|c|c|}
\hline \multicolumn{10}{|c|}{ TABLE 1 } \\
\hline \multicolumn{10}{|c|}{ True model: STUR model (1) } \\
\hline $\mathrm{T}$ & 0.00 & 0.25 & 0.50 & 0.75 & 1.00 & 1.25 & 1.50 & 1.75 & 2.00 \\
\hline 100 & 0.857 & 0.517 & 0.129 & 0.126 & 0.386 & 0.726 & 0.887 & 0.942 & 0.960 \\
\hline 200 & 0.918 & 0.632 & 0.239 & 0.330 & 0.694 & 0.893 & 0.969 & 0.987 & 0.994 \\
\hline 300 & 0.933 & 0.721 & 0.302 & 0.420 & 0.790 & 0.945 & 0.988 & 0.996 & 0.997 \\
\hline 400 & 0.945 & 0.737 & 0.384 & 0.495 & 0.825 & 0.957 & 0.991 & 0.998 & 0.999 \\
\hline 500 & 1.000 & 1.000 & 0.666 & 1.000 & 1.000 & 1.000 & 1.000 & 1.000 & 1.000 \\
\hline 1000 & 1.000 & 1.000 & 0.726 & 1.000 & 1.000 & 1.000 & 1.000 & 1.000 & 1.000 \\
\hline 2000 & 1.000 & 1.000 & 0.898 & 1.000 & 1.000 & 1.000 & 1.000 & 1.000 & 1.000 \\
\hline
\end{tabular}

\section{TABLE 2}

\begin{tabular}{|c|c|c|c|c|c|c|c|c|c|}
\hline \multicolumn{10}{|c|}{ Rejection frequencies of Robinson's (1994a) tests (with AR (1) $\mathrm{u}_{\mathrm{t}}$ ) in a STUR model } \\
\hline \multicolumn{10}{|c|}{ True model: STUR model (1) } \\
\hline $\mathrm{T}$ & 0.00 & 0.25 & 0.50 & 0.75 & 1.00 & 1.25 & 1.50 & 1.75 & 2.00 \\
\hline 100 & 0.402 & 0.752 & 0.908 & 0.959 & 0.975 & 0.988 & 0.993 & 0.995 & 0.998 \\
\hline 200 & 0.705 & 0.903 & 0.970 & 0.991 & 0.997 & 0.999 & 0.999 & 0.999 & 0.999 \\
\hline 300 & 0.793 & 0.950 & 0.991 & 0.997 & 0.999 & 1.000 & 1.000 & 1.000 & 1.000 \\
\hline 400 & 0.829 & 0.959 & 0.992 & 0.997 & 0.998 & 1.000 & 1.000 & 1.000 & 1.000 \\
\hline 500 & 0.862 & 0.960 & 0.992 & 0.999 & 0.999 & 1.000 & 1.000 & 1.000 & 1.000 \\
\hline 1000 & 0.943 & 0.991 & 0.998 & 1.000 & 1.000 & 1.000 & 1.000 & 1.000 & 1.000 \\
\hline 2000 & 0.958 & 0.991 & 0.999 & 1.000 & 1.000 & 1.000 & 1.000 & 1.000 & 1.000 \\
\hline
\end{tabular}




\section{TABLE 3}

Rejection frequencies of Robinson's (1994a) tests (with white noise $u_{t}$ ) in a STUR ${ }^{*}$ model True model: STUR $^{*}$ model in (1) and (9)

\begin{tabular}{|c|c|c|c|c|c|c|c|c|c|}
\hline $\mathrm{T}$ & 0.00 & 0.25 & 0.50 & 0.75 & 1.00 & 1.25 & 1.50 & 1.75 & 2.00 \\
\hline 100 & 0.848 & 0.583 & 0.309 & 0.259 & 0.410 & 0.579 & 0.758 & 0.861 & 0.902 \\
\hline 200 & 0.903 & 0.712 & 0.411 & 0.382 & 0.573 & 0.774 & 0.894 & 0.938 & 0.965 \\
\hline 300 & 0.941 & 0.773 & 0.477 & 0.422 & 0.650 & 0.848 & 0.942 & 0.967 & 0.984 \\
\hline 400 & 0.941 & 0.789 & 0.525 & 0.500 & 0.739 & 0.887 & 0.952 & 0.978 & 0.992 \\
\hline 500 & 0.953 & 0.789 & 0.589 & 0.546 & 0.743 & 0.889 & 0.952 & 0.980 & 0.999 \\
\hline 1000 & 0.963 & 0.853 & 0.687 & 0.668 & 0.818 & 0.917 & 0.971 & 0.986 & 0.998 \\
\hline 2000 & 0.966 & 0.883 & 0.754 & 0.746 & 0.862 & 0.941 & 0.999 & 1.000 & 1.000 \\
\hline
\end{tabular}

\section{TABLE 4}

Rejection frequencies of Robinson's (1994a) tests (with AR (1) $\mathrm{u}_{\mathrm{t}}$ ) in a STUR ${ }^{*}$ model

True model: STUR ${ }^{*}$ model in (1) and (9)

\begin{tabular}{|c|c|c|c|c|c|c|c|c|c|}
\hline $\mathrm{T}$ & 0.00 & 0.25 & 0.50 & 0.75 & 1.00 & 1.25 & 1.50 & 1.75 & 2.00 \\
\hline 100 & 0.385 & 0.571 & 0.768 & 0.867 & 0.920 & 0.949 & 0.967 & 0.974 & 0.979 \\
\hline 200 & 0.556 & 0.772 & 0.894 & 0.942 & 0.965 & 0.980 & 0.981 & 0.982 & 0.987 \\
\hline 300 & 0.632 & 0.836 & 0.937 & 0.967 & 0.987 & 0.991 & 0.992 & 0.992 & 0.994 \\
\hline 400 & 0.728 & 0.880 & 0.951 & 0.975 & 0.988 & 0.991 & 0.993 & 0.994 & 0.996 \\
\hline 500 & 0.735 & 0.883 & 0.956 & 0.988 & 0.990 & 0.999 & 0.999 & 1.000 & 1.000 \\
\hline 1000 & 0.821 & 0.927 & 0.981 & 0.995 & 0.998 & 0.999 & 1.000 & 1.000 & 1.000 \\
\hline 2000 & 0.881 & 0.959 & 0.987 & 0.999 & 0.999 & 1.000 & 1.000 & 1.000 & 1.000 \\
\hline
\end{tabular}


TABLE 5

Rejection frequencies of Robinson (1995a) tests in a simple STUR model

\begin{tabular}{|c|c|c|c|c|c|c|c|c|c|c|}
\hline $\mathrm{m}$ & $\mathrm{T} / \mathrm{d}$ & 0.00 & 0.25 & 0.50 & 0.75 & 1.00 & 1.25 & 1.50 & 1.75 & 2.00 \\
\hline \multirow{7}{*}{$\mathrm{T} / 10$} & 100 & 1.000 & 0.810 & 0.810 & 0.470 & 0.340 & 0.190 & 0.839 & 0.970 & 1.000 \\
\hline & 200 & 1.000 & 1.000 & 0.949 & 1.000 & 0.150 & 0.720 & 0.980 & 1.000 & 1.000 \\
\hline & 300 & 1.000 & 1.000 & 0.980 & 1.000 & 0.059 & 0.899 & 1.000 & 1.000 & 1.000 \\
\hline & 400 & 1.000 & 1.000 & 0.990 & 1.000 & 0.079 & 0.910 & 1.000 & 1.000 & 1.000 \\
\hline & 500 & 1.000 & 1.000 & 1.000 & 1.000 & 0.070 & 0.930 & 1.000 & 1.000 & 1.000 \\
\hline & 1000 & 1.000 & 1.000 & 1.000 & 1.000 & 0.050 & 1.000 & 1.000 & 1.000 & 1.000 \\
\hline & 2000 & 1.000 & 1.000 & 1.000 & 1.000 & 0.070 & 1.000 & 1.000 & 1.000 & 1.000 \\
\hline \multirow{7}{*}{$\mathrm{T} / 5$} & 100 & 1.000 & 1.000 & 0.920 & 1.000 & 0.140 & 0.670 & 1.000 & 1.000 & 1.000 \\
\hline & 200 & 1.000 & 1.000 & 0.970 & 1.000 & 0.079 & 0.930 & 1.000 & 1.000 & 1.000 \\
\hline & 300 & 1.000 & 1.000 & 1.000 & 1.000 & 0.079 & 0.970 & 1.000 & 1.000 & 1.000 \\
\hline & 400 & 1.000 & 1.000 & 1.000 & 1.000 & 0.079 & 0.990 & 1.000 & 1.000 & 1.000 \\
\hline & 500 & 1.000 & 1.000 & 1.000 & 1.000 & 0.120 & 1.000 & 1.000 & 1.000 & 1.000 \\
\hline & 1000 & 1.000 & 1.000 & 1.000 & 1.000 & 0.059 & 1.000 & 1.000 & 1.000 & 1.000 \\
\hline & 2000 & 1.000 & 1.000 & 1.000 & 1.000 & 0.012 & 1.000 & 1.000 & 1.000 & 1.000 \\
\hline \multirow{7}{*}{$\mathrm{T} / 4$} & 100 & 1.000 & 1.000 & 0.920 & 1.000 & 0.200 & 0.790 & 1.000 & 1.000 & 1.000 \\
\hline & 200 & 1.000 & 1.000 & 0.970 & 1.000 & 0.090 & 0.949 & 1.000 & 1.000 & 1.000 \\
\hline & 300 & 1.000 & 1.000 & 1.000 & 1.000 & 0.079 & 0.980 & 1.000 & 1.000 & 1.000 \\
\hline & 400 & 1.000 & 1.000 & 1.000 & 1.000 & 0.079 & 1.000 & 1.000 & 1.000 & 1.000 \\
\hline & 500 & 1.000 & 1.000 & 1.000 & 1.000 & 0.080 & 1.000 & 1.000 & 1.000 & 1.000 \\
\hline & 1000 & 1.000 & 1.000 & 1.000 & 1.000 & 0.039 & 1.000 & 1.000 & 1.000 & 1.000 \\
\hline & 2000 & 1.000 & 1.000 & 1.000 & 1.000 & 0.059 & 1.000 & 1.000 & 1.000 & 1.000 \\
\hline \multirow{7}{*}{$T / 3$} & 100 & 1.000 & 1.000 & 0.959 & 1.000 & 0.110 & 0.880 & 1.000 & 1.000 & 1.000 \\
\hline & 200 & 1.000 & 1.000 & 1.000 & 1.000 & 0.051 & 0.970 & 1.000 & 1.000 & 1.000 \\
\hline & 300 & 1.000 & 1.000 & 1.000 & 1.000 & 0.059 & 0.990 & 1.000 & 1.000 & 1.000 \\
\hline & 400 & 1.000 & 1.000 & 1.000 & 1.000 & 0.070 & 1.000 & 1.000 & 1.000 & 1.000 \\
\hline & 500 & 1.000 & 1.000 & 1.000 & 1.000 & 0.080 & 1.000 & 1.000 & 1.000 & 1.000 \\
\hline & 1000 & 1.000 & 1.000 & 1.000 & 1.000 & 0.059 & 1.000 & 1.000 & 1.000 & 1.000 \\
\hline & 2000 & 1.000 & 1.000 & 1.000 & 1.000 & 0.079 & 1.000 & 1.000 & 1.000 & 1.000 \\
\hline \multirow{7}{*}{$(T / 2)-1$} & 100 & 1.000 & 1.000 & 0.990 & 1.000 & 0.059 & 0.970 & 1.000 & 1.000 & 1.000 \\
\hline & 200 & 1.000 & 1.000 & 1.000 & 1.000 & 0.039 & 1.000 & 1.000 & 1.000 & 1.000 \\
\hline & 300 & 1.000 & 1.000 & 1.000 & 1.000 & 0.039 & 0.990 & 1.000 & 1.000 & 1.000 \\
\hline & 400 & 1.000 & 1.000 & 1.000 & 1.000 & 0.070 & 1.000 & 1.000 & 1.000 & 1.000 \\
\hline & 500 & 1.000 & 1.000 & 1.000 & 1.000 & 0.050 & 1.000 & 1.000 & 1.000 & 1.000 \\
\hline & 1000 & 1.000 & 1.000 & 1.000 & 1.000 & 0.030 & 1.000 & 1.000 & 1.000 & 1.000 \\
\hline & 2000 & 1.000 & 1.000 & 1.000 & 1.000 & 0.059 & 1.000 & 1.000 & 1.000 & 1.000 \\
\hline
\end{tabular}




\begin{tabular}{|c|c|c|c|c|c|c|c|c|c|c|}
\hline \multicolumn{11}{|c|}{ TABLE 6} \\
\hline \multicolumn{11}{|c|}{ Rejection frequencies of Robinson (1995a) tests in a simple STUR ${ }^{*}$ model } \\
\hline $\mathrm{m}$ & $\mathrm{T} / \mathrm{d}$ & 0.00 & 0.25 & 0.50 & 0.75 & 1.00 & 1.25 & 1.50 & 1.75 & 2.00 \\
\hline \multirow{7}{*}{$\mathrm{T} / 10$} & 100 & 1.000 & 0.140 & 0.140 & 0.005 & 0.860 & 0.860 & 1.000 & 1.000 & 1.000 \\
\hline & 200 & 1.000 & 1.000 & 0.051 & 1.000 & 0.949 & 0.990 & 1.000 & 1.000 & 1.000 \\
\hline & 300 & 1.000 & 1.000 & 0.039 & 1.000 & 0.970 & 0.990 & 1.000 & 1.000 & 1.000 \\
\hline & 400 & 1.000 & 1.000 & 0.029 & 1.000 & 0.970 & 1.000 & 1.000 & 1.000 & 1.000 \\
\hline & 500 & 1.000 & 1.000 & 0.029 & 1.000 & 0.970 & 1.000 & 1.000 & 1.000 & 1.000 \\
\hline & 1000 & 1.000 & 1.000 & 0.012 & 1.000 & 1.000 & 1.000 & 1.000 & 1.000 & 1.000 \\
\hline & 2000 & 1.000 & 1.000 & 0.012 & 1.000 & 1.000 & 1.000 & 1.000 & 1.000 & 1.000 \\
\hline \multirow{7}{*}{$\mathrm{T} / 5$} & 100 & 1.000 & 1.000 & 0.170 & 1.000 & 0.870 & 0.930 & 0.990 & 1.000 & 1.000 \\
\hline & 200 & 1.000 & 1.000 & 0.100 & 1.000 & 0.930 & 0.980 & 0.990 & 1.000 & 1.000 \\
\hline & 300 & 1.000 & 1.000 & 0.090 & 1.000 & 0.930 & 0.990 & 1.000 & 1.000 & 1.000 \\
\hline & 400 & 1.000 & 1.000 & 0.079 & 1.000 & 0.971 & 0.990 & 1.000 & 1.000 & 1.000 \\
\hline & 500 & 1.000 & 1.000 & 0.070 & 1.000 & 0.940 & 0.990 & 1.000 & 1.000 & 1.000 \\
\hline & 1000 & 1.000 & 1.000 & 0.039 & 1.000 & 0.959 & 1.000 & 1.000 & 1.000 & 1.000 \\
\hline & 2000 & 1.000 & 1.000 & 0.019 & 1.000 & 1.000 & 1.000 & 1.000 & 1.000 & 1.000 \\
\hline \multirow{7}{*}{$T / 4$} & 100 & 1.000 & 1.000 & 0.230 & 0.980 & 0.820 & 0.940 & 0.980 & 1.000 & 1.000 \\
\hline & 200 & 1.000 & 1.000 & 0.160 & 1.000 & 0.880 & 0.970 & 0.990 & 1.000 & 1.000 \\
\hline & 300 & 1.000 & 1.000 & 0.140 & 1.000 & 0.899 & 0.959 & 1.000 & 1.000 & 1.000 \\
\hline & 400 & 1.000 & 1.000 & 0.090 & 1.000 & 0.940 & 0.990 & 1.000 & 1.000 & 1.000 \\
\hline & 500 & 1.000 & 1.000 & 0.100 & 1.000 & 0.910 & 0.990 & 1.000 & 1.000 & 1.000 \\
\hline & 1000 & 1.000 & 1.000 & 0.110 & 1.000 & 0.889 & 1.000 & 1.000 & 1.000 & 1.000 \\
\hline & 2000 & 1.000 & 1.000 & 0.130 & 1.000 & 1.000 & 1.000 & 1.000 & 1.000 & 1.000 \\
\hline \multirow{7}{*}{$T / 3$} & 100 & 1.000 & 1.000 & 0.300 & 1.000 & 0.750 & 0.959 & 0.970 & 1.000 & 1.000 \\
\hline & 200 & 1.000 & 1.000 & 0.259 & 1.000 & 0.790 & 0.979 & 1.000 & 1.000 & 1.000 \\
\hline & 300 & 1.000 & 1.000 & 0.209 & 1.000 & 0.829 & 0.980 & 0.990 & 1.000 & 1.000 \\
\hline & 400 & 1.000 & 1.000 & 0.190 & 0.990 & 0.850 & 0.970 & 1.000 & 1.000 & 1.000 \\
\hline & 500 & 1.000 & 1.000 & 0.170 & 1.000 & 0.860 & 0.990 & 1.000 & 1.000 & 1.000 \\
\hline & 1000 & 1.000 & 1.000 & 0.200 & 1.000 & 0.829 & 0.980 & 1.000 & 1.000 & 1.000 \\
\hline & 2000 & 1.000 & 1.000 & 0.232 & 1.000 & 1.000 & 1.000 & 1.000 & 1.000 & 1.000 \\
\hline \multirow{7}{*}{$(\mathrm{T} / 2)-1$} & 100 & 1.000 & 1.000 & 0.411 & 1.000 & 0.671 & 0.959 & 0.959 & 1.000 & 1.000 \\
\hline & 200 & 1.000 & 1.000 & 0.479 & 1.000 & 0.630 & 0.959 & 0.980 & 1.000 & 1.000 \\
\hline & 300 & 1.000 & 1.000 & 0.410 & 1.000 & 0.670 & 0.970 & 1.000 & 1.000 & 1.000 \\
\hline & 400 & 1.000 & 1.000 & 0.360 & 0.990 & 0.730 & 0.970 & 0.990 & 1.000 & 1.000 \\
\hline & 500 & 1.000 & 1.000 & 0.410 & 1.000 & 0.690 & 0.980 & 0.990 & 1.000 & 1.000 \\
\hline & 1000 & 1.000 & 1.000 & 0.430 & 1.000 & 0.670 & 0.959 & 1.000 & 1.000 & 1.000 \\
\hline & 2000 & 1.000 & 1.000 & 0.497 & 1.000 & 1.000 & 1.000 & 1.000 & 1.000 & 1.000 \\
\hline
\end{tabular}


TABLE 7

\begin{tabular}{|c|c|c|c|c|c|c|c|c|c|}
\hline \multicolumn{8}{|c|}{ Rejection frequencies of Robinson's $(1994 \mathrm{a})$ tests (with white noise $\mathrm{u}_{\mathrm{t}}$ ) in a STUR model } \\
\hline \multicolumn{8}{|c|}{ True model: STUR model with a $\mathrm{t}_{3}$ distribution for $\varepsilon_{\mathrm{t}}$} \\
\hline $\mathrm{T}$ & 0.00 & 0.25 & 0.50 & 0.75 & 1.00 & 1.25 & 1.50 & 1.75 & 2.00 \\
\hline 100 & 0.853 & 0.557 & 0.155 & 0.116 & 0.378 & 0.707 & 0.874 & 0.941 & 0.977 \\
\hline 200 & 0.911 & 0.676 & 0.240 & 0.237 & 0.679 & 0.875 & 0.965 & 0.984 & 0.993 \\
\hline 300 & 0.914 & 0.731 & 0.352 & 0.414 & 0.766 & 0.927 & 0.970 & 0.988 & 0.996 \\
\hline 400 & 0.966 & 0.749 & 0.339 & 0.511 & 0.837 & 0.957 & 0.986 & 0.997 & 0.997 \\
\hline 500 & 0.964 & 0.793 & 0.418 & 0.523 & 0.868 & 0.973 & 0.994 & 0.999 & 0.999 \\
\hline 1000 & 0.978 & 0.852 & 0.555 & 0.671 & 0.941 & 0.991 & 0.998 & 0.999 & 0.999 \\
\hline 2000 & 1.000 & 0.999 & 0.997 & 0.999 & 1.000 & 1.000 & 1.000 & 1.000 & 1.000 \\
\hline
\end{tabular}

\section{TABLE 8}

Rejection frequencies of Robinson's (1994a) tests (with AR (1) $u_{t}$ ) in a STUR model

True model: STUR model with a $\mathrm{t}_{3}$ distribution for $\varepsilon_{\mathrm{t}}$

\begin{tabular}{|c|c|c|c|c|c|c|c|c|c|}
\hline $\mathrm{T}$ & 0.00 & 0.25 & 0.50 & 0.75 & 1.00 & 1.25 & 1.50 & 1.75 & 2.00 \\
\hline 100 & 0.3931 & 0.715 & 0.875 & 0.957 & 0.985 & 0.997 & 0.999 & 0.999 & 0.999 \\
\hline 200 & 0.672 & 0.899 & 0.972 & 0.990 & 0.995 & 1.000 & 1.000 & 1.000 & 1.000 \\
\hline 300 & 0.769 & 0.930 & 0.985 & 0.993 & 1.000 & 1.000 & 1.000 & 1.000 & 1.000 \\
\hline 400 & 0.838 & 0.958 & 0.984 & 0.993 & 1.000 & 0.999 & 1.000 & 1.000 & 1.000 \\
\hline 500 & 0.864 & 0.971 & 0.995 & 0.997 & 1.000 & 1.000 & 1.000 & 1.000 & 1.000 \\
\hline 1000 & 0.945 & 0.996 & 1.000 & 1.000 & 1.000 & 1.000 & 1.000 & 1.000 & 1.000 \\
\hline 2000 & 0.998 & 0.999 & 1.000 & 1.000 & 1.000 & 1.000 & 1.000 & 1.000 & 1.000 \\
\hline
\end{tabular}




\section{TABLE 9}

Rejection frequencies of Robinson's (1994a) tests (with white noise $u_{t}$ ) in a STUR ${ }^{*}$ model

True model: STUR $^{*}$ model with a $\mathrm{t}_{3}$ distribution for $\varepsilon_{\mathrm{t}}$

\begin{tabular}{|c|c|c|c|c|c|c|c|c|c|}
\hline $\mathrm{T}$ & 0.00 & 0.25 & 0.50 & 0.75 & 1.00 & 1.25 & 1.50 & 1.75 & 2.00 \\
\hline 100 & 0.871 & 0.589 & 0.261 & 0.221 & 0.371 & 0.570 & 0.738 & 0.843 & 0.893 \\
\hline 200 & 0.932 & 0.714 & 0.382 & 0.352 & 0.548 & 0.785 & 0.882 & 0.947 & 0.977 \\
\hline 300 & 0.922 & 0.754 & 0.490 & 0.472 & 0.679 & 0.849 & 0.932 & 0.967 & 0.984 \\
\hline 400 & 0.956 & 0.775 & 0.519 & 0.525 & 0.730 & 0.888 & 0.955 & 0.985 & 0.994 \\
\hline 500 & 0.955 & 0.796 & 0.590 & 0.545 & 0.745 & 0.907 & 0.975 & 0.986 & 0.997 \\
\hline 1000 & 0.966 & 0.876 & 0.683 & 0.677 & 0.835 & 0.929 & 0.975 & 0.993 & 0.998 \\
\hline 2000 & 0.998 & 0.996 & 0.983 & 0.984 & 0.998 & 1.000 & 1.000 & 1.000 & 1.000 \\
\hline
\end{tabular}

\section{TABLE 10}

Rejection frequencies of Robinson's (1994a) tests (with AR (1) $\mathrm{u}_{\mathrm{t}}$ ) in a STUR ${ }^{*}$ model

True model: STUR $^{*}$ model with a $t_{3}$ distribution for $\varepsilon_{t}$

\begin{tabular}{|c|c|c|c|c|c|c|c|c|c|}
\hline $\mathrm{T}$ & 0.00 & 0.25 & 0.50 & 0.75 & 1.00 & 1.25 & 1.50 & 1.75 & 2.00 \\
\hline 100 & 0.364 & 0.590 & 0.774 & 0.871 & 0.934 & 0.956 & 0.979 & 0.983 & 0.985 \\
\hline 200 & 0.555 & 0.782 & 0.898 & 0.940 & 0.972 & 0.979 & 0.980 & 0.986 & 0.999 \\
\hline 300 & 0.639 & 0.842 & 0.939 & 0.967 & 0.985 & 0.998 & 0.998 & 0.997 & 0.997 \\
\hline 400 & 0.715 & 0.874 & 0.948 & 0.977 & 0.985 & 0.991 & 0.993 & 0.995 & 0.997 \\
\hline 500 & 0.735 & 0.887 & 0.949 & 0.979 & 0.987 & 0.994 & 0.995 & 0.994 & 0.998 \\
\hline 1000 & 0.819 & 0.937 & 0.983 & 0.997 & 0.998 & 1.000 & 0.999 & 0.999 & 0.999 \\
\hline 2000 & 0.989 & 0.999 & 1.000 & 1.000 & 1.000 & 1.000 & 1.000 & 1.000 & 1.000 \\
\hline
\end{tabular}


TABLE 11

\begin{tabular}{|c|c|c|c|c|c|c|c|c|c|}
\hline \multicolumn{8}{|c|}{ Rejection frequencies of Robinson's $(1994 \mathrm{a})$ tests (with white noise $\mathrm{u}_{\mathrm{t}}$ ) in a STUR model } \\
\hline \multicolumn{8}{|c|}{ True model: Seasonal STUR model $(16)$} \\
\hline $\mathrm{T}$ & 0.00 & 0.25 & 0.50 & 0.75 & 1.00 & 1.25 & 1.50 & 1.75 & 2.00 \\
\hline 100 & 0.351 & 0.150 & 0.046 & 0.071 & 0.229 & 0.482 & 0.683 & 0.801 & 0.874 \\
\hline 200 & 0.792 & 0.459 & 0.188 & 0.241 & 0.526 & 0.786 & 0.897 & 0.944 & 0.963 \\
\hline 300 & 0.898 & 0.610 & 0.258 & 0.333 & 0.662 & 0.868 & 0.947 & 0.973 & 0.982 \\
\hline 400 & 0.930 & 0.667 & 0.300 & 0.399 & 0.740 & 0.926 & 0.968 & 0.989 & 0.995 \\
\hline 500 & 0.931 & 0.705 & 0.356 & 0.454 & 0.784 & 0.934 & 0.977 & 0.987 & 0.996 \\
\hline 1000 & 0.963 & 0.791 & 0.471 & 0.600 & 0.882 & 0.975 & 0.995 & 0.997 & 0.998 \\
\hline 2000 & 0.999 & 0.976 & 0.945 & 0.869 & 0.991 & 0.993 & 0.999 & 1.000 & 1.000 \\
\hline
\end{tabular}

TABLE 12

Rejection frequencies of Robinson's (1994) tests (with AR (1) $\mathrm{u}_{\mathrm{t}}$ ) in a STUR model

True model: Seasonal STUR model (16)

\begin{tabular}{|c|c|c|c|c|c|c|c|c|c|}
\hline $\mathrm{T}$ & 0.00 & 0.25 & 0.50 & 0.75 & 1.00 & 1.25 & 1.50 & 1.75 & 2.00 \\
\hline 100 & 0.083 & 0.157 & 0.339 & 0.654 & 0.852 & 0.934 & 0.973 & 0.988 & 0.991 \\
\hline 200 & 0.289 & 0.232 & 0.488 & 0.800 & 0.935 & 0.975 & 0.987 & 0.993 & 0.998 \\
\hline 300 & 0.508 & 0.282 & 0.546 & 0.872 & 0.964 & 0.981 & 0.989 & 0.995 & 0.997 \\
\hline 400 & 0.638 & 0.370 & 0.618 & 0.914 & 0.979 & 0.996 & 0.999 & 0.999 & 0.999 \\
\hline 500 & 0.684 & 0.410 & 0.666 & 0.928 & 0.984 & 0.995 & 0.998 & 0.999 & 0.999 \\
\hline 1000 & 0.798 & 0.701 & 0.893 & 0.995 & 0.999 & 1.000 & 1.000 & 1.000 & 1.000 \\
\hline 2000 & 0.988 & 0.982 & 0.994 & 1.000 & 1.000 & 1.000 & 1.000 & 1.000 & 1.000 \\
\hline
\end{tabular}




\begin{tabular}{|c|c|c|c|c|c|c|c|c|c|}
\hline \multicolumn{10}{|c|}{ TABLE 13 } \\
\hline \multicolumn{10}{|c|}{ True model: Seasonal STUR ${ }^{*}$ model (16) and (17) } \\
\hline $\mathrm{T}$ & 0.00 & 0.25 & 0.50 & 0.75 & 1.00 & 1.25 & 1.50 & 1.75 & 2.00 \\
\hline 100 & 0.353 & 0.213 & 0.120 & 0.102 & 0.209 & 0.367 & 0.528 & 0.635 & 0.716 \\
\hline 200 & 0.827 & 0.570 & 0.323 & 0.296 & 0.449 & 0.654 & 0.788 & 0.854 & 0.892 \\
\hline 300 & 0.896 & $0-691$ & 0.460 & 0.395 & 0.560 & 0.745 & 0.866 & 0.908 & 0.926 \\
\hline 400 & 0.931 & 0.752 & 0.464 & 0.434 & 0.628 & 0.811 & 0.903 & 0.952 & 0.967 \\
\hline 500 & 0.927 & 0.771 & 0.513 & 0.485 & 0.676 & 0.837 & 0.919 & 0.957 & 0.971 \\
\hline 1000 & 0.954 & 0.912 & 0.893 & 0.877 & 0.934 & 0.995 & 1.000 & 1.000 & 1.000 \\
\hline 2000 & 1.000 & 0.999 & 0.994 & 0.991 & 0.996 & 1.000 & 1.000 & 1.000 & 1.000 \\
\hline
\end{tabular}

\section{TABLE 14}

Rejection frequencies of Robinson's (1994a) tests (with AR (1) $\mathrm{u}_{\mathrm{t}}$ ) in a STUR ${ }^{*}$ model

\begin{tabular}{|c|c|c|c|c|c|c|c|c|c|}
\hline \multicolumn{10}{|c|}{ True model: Seasonal STUR ${ }^{*}$ model (16) and (17) } \\
\hline $\mathrm{T}$ & 0.00 & 0.25 & 0.50 & 0.75 & 1.00 & 1.25 & 1.50 & 1.75 & 2.00 \\
\hline 100 & 0.105 & 0.133 & 0.285 & 0.490 & 0.688 & 0.803 & 0.861 & 0.895 & 0.912 \\
\hline 200 & 0.306 & 0.227 & 0.379 & 0.655 & 0.822 & 0.893 & 0.920 & 0.930 & 0.942 \\
\hline 300 & 0.587 & 0.397 & 0.476 & 0.728 & 0.870 & 0.924 & 0.946 & 0.959 & 0.965 \\
\hline 400 & 0.677 & 0.424 & 0.528 & 0.807 & 0.916 & 0.956 & 0.972 & 0.978 & 0.981 \\
\hline 500 & 0.722 & 0.502 & 0.564 & 0.821 & 0.934 & 0.960 & 0.978 & 0.983 & 0.988 \\
\hline 1000 & 0.912 & 0.823 & 0.856 & 0.912 & 0.974 & 0.999 & 1.000 & 1.000 & 1.000 \\
\hline 2000 & 0.994 & 0.946 & 0.957 & 0.996 & 1.000 & 1.000 & 1.000 & 1.000 & 1.000 \\
\hline
\end{tabular}

